\title{
2. O ALIENISTA E A SAÚDE MENTAL, O NORMAL E O PATOLÓGICO: UM DIÁLOGO COM QUINE E OS ENUNCIADOS OBSERVACIONAIS
}

\author{
Emerson de Lima Pinto ${ }^{1}$ \\ Joseane Mariéle Schuck Pinto ${ }^{2}$
}

RESUMO: A análise da obra, o alienista de Machado de Assis sobre a ciência, a saúde e a loucura em reflexão sobre o empirismo de Quine que sempre representou um debate demonstrando a insuficiência e preconceitos, em relação à noção de racionalidade científica adotado pelos empiristas clássicos do século XX. O sistema conceitual proposto por Quine sobre os denominados Enunciados Observacionais e sua visão holística retratado por STEIN. Verificar Victor Kraft (sentenças protocolares) e sua confrontação com o capítulo $\mathrm{V}$ (O problema da base empírica) da Lógica da Pesquisa Científica (1934) do Popper, que fala dos Enunciados Observacionais e o Trilema de Fries (que estabelece que fiquem presos entre o psicologismo (empirismo), o dogmatismo (realismo ingênuo) e o regresso ao infinito (coerentismo) quando tentamos estabelecer uma base empírica para as ciências) se torna exercício importante, a fim de investigar o empirismo presente nas ciência naturais.

Palavras-chave: Alienista - loucura - empirismo.

ABSTRACT: The analysis of the work of the psychiatrist Machado de Assis on science, health and madness in the reflection on the empiricism of Quine has always represented an debate demonstrating the inadequacy and prejudices in relation to the notion of scientific rationality adopted by empiricists classics of the twentieth century. The conceptual system proposed by Quine called on Utterances Observational and its holistic vision portrayed by STEIN. Check Victor Kraft (protocol sentences) and his confrontation with Chapter $V$ (The problem of the empirical basis) Logic of Scientific Research (1934) of Popper, who speaks of Observational Statements of Trilemma and Fries (establishing that are stuck between psychologism (empiricism), dogmatism (naive realism) and return to infinity (coherentism) when trying to establish an empirical basis for the sciences) becomes important exercise in order to investigate this empiricism in natural science.

Keywords: Psychiatrist - madness - empiricism.

\footnotetext{
${ }^{1}$ Advogado. Doutorando em Filosofia UNISINOS. Mestre em Direito Público UNISINOS. Especialista em Ciências Penais PUCRS. Professor no Curso de Graduação e Direito no CESUCA e UNISINOS em Relações Internacionais no UNILASALLE. Pesquisador do CESUCA.

${ }^{2}$ Advogada. Pós graduanda pelo Programa de Pós graduação em Relações Internacionais e Diplomacia da Universidade do Vale do Rio dos Sinos - UNISINOS. Autora do Caderno IHU Ideias, Ano 11 - № 186 - 2013. ISSN:1679-0316, com o título: A hospitalidade frente ao processo de reassentamento solidário aos refugiados.
} 


\section{Introdução}

O presente ensaio visa trazer à tona a obra de Machado de Assis, $O$ Alienista $^{3}$, na qual se vislumbra a luta incessante do médico (cientista) Dr. Simão Bacamarte na busca de (des)velar a loucura (patologias mentais) por meio da ciência, assim como em relação a saúde mental nota-se a dificuldade em diferenciar o normal do patológico. Nesse processo o personagem central, o médico/cientista, adota um modelo empirista e ao mesmo tempo dogmatista que the coloca numa posição incomum junto à sociedade (Itaguaí) e suas relações de poder. Nesse sentido, o empirismo de Quine, que ao longo do tempo sempre representou um debate relevante demonstrando a insuficiência e preconceitos, em relação à noção de racionalidade científica adotado pelos empiristas clássicos do século XX. O sistema conceitual proposto por Quine sobre os denominados Enunciados Observacionais e sua visão holística retratado por STEIN na obra VAN ORMAN QUINE: Epistemologia, Semântica e Ontologia que analisa a obra de Quine, vêm demonstrar tal fato. Verificar Victor Kraft (sentenças protocolares) e sua confrontação com o capítulo V (O problema da base empírica) da Lógica da Pesquisa Científica (1934) do Popper, que fala dos Enunciados Observacionais e o Trilema de Fries (que estabelece que fiquem presos entre o psicologismo (empirismo), o dogmatismo (realismo ingênuo) e o regresso ao infinito (coerentismo) quando tentamos estabelecer uma base empírica para as ciências) se torna exercício importante, a fim de investigar o empirismo nas ciências naturais. Importa destacar ao longo destas considerações a predisposição de Quine em superar ideias dogmáticas acerca do tema.

Ademais, sobre como a ciência ${ }^{4}$ deve ser compreendida por Popper, desta forma a obra revela sua compreensão sobre tal conceito que de certo modo nos possibilita verificar a compreensão mais lacunosa e instável do autor até a compreensão de Quine, e a relação que a sua noção de experiência e o fato de como deveria ocorrer uma dispensabilidade de um discurso sobre a construção os objetos científicos como processo de construção teórica.

\footnotetext{
${ }^{3}$ MACHADO DE ASSIS, Joaquim Maria. O alienista. Porto Alegre: LPM, 2010. p. 13.

${ }^{4}$ POPPER, Karl. Lógica da Pesquisa Cientifica, p. 107. A Ciência pode ser encarada sob vários prismas e não apenas sob o ângulo da Epistemologia; podemos encará-la, por exemplo, como um fenômeno biológico ou sociológico. Nesses termos, caberia descrevê-la como ferramenta ou instrumento, comparável, talvez, a alguns que integram nosso aparelhamento industrial. A Ciência pode ser olhada como um meio de produção - como a última palavra em "produção indireta". (...) a Ciência não se relaciona mais estreitamente com a "nossa experiência" do que outros instrumentos ou meios de produção. Reconhecidamente, não há incorreção em dizer que a Ciência é "um instrumento" cujo propósito está em “... predizer, com base em experiências dadas ou imediatas, experiências posteriores e, tanto quanto possível, submetê-las a controle". (grifo nosso)
} 


\section{O normal e o patológico}

Primeiramente, insta esclarecer que em relação à temática da saúde mental ${ }^{5}$, vislumbramse dificuldades em construir uma classificação universal acerca das desordens mentais, visto que o cenário internacional é constituído por culturas diferentes, bem como por conjunturas políticas diversas, vindo corroborar o lobby advindo de indústrias farmacêuticas. Portadores de doença mental foram acometidos de um grande desrespeito aos seus direitos humanos, face a tratamentos desumanos e degradantes pelos quais foram submetidos, enquanto pacientes. No entanto, nas últimas décadas ocorreram avanços nesse sentido, nos quais a tendência mundial é humanizar os tratamentos de saúde mental, através da extinção de manicômios e da implementação de um novo sistema chamado Centro de Atenção Psicossocial - CAPS, deixando de lado pré-conceitos estabelecidos pela sociedade no tocante a portadores de alguma enfermidade psíquica.

A partir disso, verifica-se que não existe um padrão universal de normalidade, definindo o que é ser ou não uma pessoa normal, uma vez que realizar tal diferenciação certamente não é uma tarefa fácil, face à multiculturaliedade que nos rodeia, além de outros fatores que contribuem para esta (in)definição, como por exemplo, não haver um padrão definido do que é uma pessoa anormal, vindo corroborar Machado de Assis: Não se sabia já quem estava são, nem quem estava doido. ${ }^{6}$ Nesse sentido, a própria literatura médica tem dificuldade de dar um conceito fechado, pois a normalidade pode ser ausência de alguma patologia, o indivíduo pode não apresentar algum tipo de transtorno mental, também pode ser considerada como um bem estar físico e mental, mas nada impede que alguma patologia venha a se manifestar posteriormente.

Definir a normalidade como sendo algo universal é uma ideia ultrapassada, fará com que os pré-conceitos sejam reinseridos em um contexto de inovações e avanços abrangendo questões

\footnotetext{
${ }^{5}$ Saúde Mental: "É um direito fundamental do cidadão, previsto na Constituição Federal para assegurar bem-estar mental, integridade psíquica e pleno desenvolvimento intelectual e emocional. No Brasil, o direito à saúde mental é amparado pela Lei e já conta com o acesso gratuito e facilitado a vários serviços públicos de atenção e auxílio. Mas vale lembrar que depende, sobretudo, da existência de condições para uma vida digna, contando, assim, com a constante articulação de indivíduos, comunidades e da sociedade como um todo para a construção de uma realidade social mais justa." Disponível em: http://pfdc.pgr.mpf.gov.br/atuacao-e-conteudos-de-apoio/publicacoes/saude mental/direito_saude_mental_2012/, acesso em 25 de Maio de 2013.

${ }^{6}$ MACHADO DE ASSIS, Joaquim Maria. O alienista. Porto Alegre: LPM, 2010. p. 45.
} 
ligadas a saúde física e mental. Vem corroborar a lição de Canguilhem ${ }^{7}$, quando refere que: "um ser vivo é normal num determinado meio na medida que ele é a solução morfológica e funcional encontrada pela vida para responder às exigências do meio." Assim, verifica-se que o patológico, não necessariamente é considerado anormal, mas pode vir a ser influenciado pelo meio em que vive, bem como pelas circunstâncias emocional ou social as quais este se encontra submetido, vindo a causar alguma perturbação.

Em relação à psiquiatria no Brasil, vale referir que seu surgimento se deu pela necessidade de resguardar a população contra àqueles que supostamente eram caracterizados como anormais, ou seja, eram vistos pela sociedade como doentes mentais, e sua principal finalidade era a de isolar estas pessoas. Nesse sentido, a obra literária vem corroborar ao referir que: De todas as vilas e arraiais vizinhos afluíam loucos à Casa Verde. Ao cabo de quatro meses, a Casa Verde era uma povoação. O Padre Lopes confessou que não imaginara a existência de tantos doidos no mundo, e menos ainda o inexplicável de alguns casos. ${ }^{8}$ Assim, verifica-se que tal disciplina científica não objetivava a cura para aqueles acometidos de transtornos mentais, mais sim, desejava excluí-los do seio da sociedade. ${ }^{9}$ Rocha ${ }^{10}$ refere que "é a psiquiatria que cria espaço próprio para o enclausuramento do louco - capaz de dominá-lo e submete-lo." Estes lugares de clausura eram os hospitais psiquiátricos ${ }^{11}$ também denominados asilos, hospícios e manicômios, salientando a obra de Machado de Assis que aduz: A Casa Verde é um cárcere privado, disse um médico em clínica. ${ }^{12}$

A saúde mental passou a ser preocupação no Brasil a partir da década de 1970 , onde denúncias à afronta aos direitos humanos de pacientes internos em Institutos Psiquiátricos começaram a emergir, surgindo um forte movimento social, composto por pessoas com longo histórico de internações, trabalhadores integrantes do movimento sanitário, sindicalistas, associações de familiares, entre outros, em prol da defesa dos direitos destes pacientes. ${ }^{13}$ Iniciou-

\footnotetext{
${ }^{7}$ CANGUILHEM, G. O normal e o patológico, trad. Maria Thereza Redig de Carvalho Barrocas e Luiz Octavio Ferreira Barreto Leite. - 4a. Ed.- Rio de Janeiro, Forense Universitária.

${ }^{8}$ MACHADO DE ASSIS, Joaquim Maria. O alienista. Porto Alegre: LPM, 2010. p. 19.

9 ROCHA, Gilberto S. - Introdução ao nascimento da psicanálise no Brasil. Rio de Janeiro,Forense Universitária, 1989, p. 13

${ }^{10}$ Ibid. p. 15.

11 “Hospital Psiquiátrico é uma instituição onde são internadas as pessoas com transtornos mentais para tratamento, semelhante aos antigos manicômios onde os "loucos" recebiam cuidados médicos e permaneciam isolados do restante da sociedade. Atualmente vêm sendo cada vez mais substituídos por uma rede de serviços de saúde mental contrária a essa lógica do confi namento. Disponível em: http://pfdc.pgr.mpf.gov.br/atuacao-e-conteudos-de-apoio/publicacoes/saudemental/direito_saude_mental_2012/, acesso em 25 de Maio de 2013.

12 MACHADO DE ASSIS, Joaquim Maria. O alienista. Porto Alegre: LPM, 2010. p. 39.

${ }^{13}$ BRASIL. Ministério da Saúde. Reforma Psiquiátrica e política de Saúde Mental no Brasil. Secretaria de Atenção à Saúde. DAPE. Coordenação Geral de Saúde Mental. Reforma psiquiátrica e política de saúde 
se, portanto a Reforma Psiquiátrica ${ }^{14}$, e no final de 1987 realiza-se o II Congresso Nacional do Movimento de Trabalhadores em Saúde Mental (MTSM) em Bauru, SP, no qual se concretiza o Movimento de Luta Antimanicomial, nesta esteira vem ao encontro à lição de Amarantes $^{15}$, senão vejamos: "Enfim, a nova etapa consolidada no Congresso de Bauru, repercutiu em muitos âmbitos: no modelo assistencial, na ação cultural e na ação jurídico-política. No âmbito do modelo assistencial, a trajetória é marcada pelo surgimento de novas modalidades de atenção, que passaram a representar uma alternativa real ao modelo psiquiátrico tradicional."

Nota-se que este período, trouxe o nascimento do primeiro CAPS (Centro de Atenção Psicossocial) no Brasil, na cidade de São Paulo, em 1987, e o início de um processo de intervenção, em 1989, da Secretaria Municipal de Saúde de Santos/SP no hospital psiquiátrico Casa de Saúde Anchieta, local de maus-tratos e mortes de pacientes. E, ainda neste ano o Deputado Paulo Delgado propõe o Projeto de Lei, a fim que se regulamente os direitos de pessoas com transtornos mentais e a extinção progressiva dos manicômios no país. No entanto, no ano de 2001 o projeto é aprovado pelo Congresso Nacional, surgindo a Lei Federal 10.216/2001 que redireciona o amparo em saúde mental, privilegiando o oferecimento de tratamento em serviços de base comunitária, dispõe sobre a proteção e os direitos das pessoas com transtornos mentais, porém não estabelece estruturas claras para a progressiva extinção dos manicômios. No governo do Presidente Lula, em 2003 é implantado um programa denominado "De volta pra casa"16, impulsionando a Reforma Psiquiátrica no país.

mental no Brasil. Documento apresentado à Conferência Regional de Reforma dos Serviços de Saúde Mental: 15 anos depois de Caracas. OPAS. Brasília, novembro de 2005.

${ }^{14}$ Reforma Psiquiátrica ou Luta Antimanicomial são nomes genéricos dados a uma grandemobilização social que já dura mais de duas décadas e vem propondo a reformulação das políticas públicas de saúde mental, de modo a abandonar o modelo asilar - considerado invasivo e opressor, fundado sobre a discriminação e a segregação de pessoas retiradas de seus campos de convivência, privadas de liberdade e tolhidas no exercício de sua singularidade e cidadania - para substituí-lo por um conjunto de serviços abertos e comunitários que devem garantir à pessoa com transtorno mental o cuidado necessário para viver com segurança em liberdade, no convívio familiar e social tanto quanto possível. Disponível em: http://pfdc.pgr.mpf.gov.br/atuacao-e-conteudos-de-apoio/publicacoes/saudemental/direito_saude_mental_2012/, acesso em 25 de Maio de 2013.

${ }^{15}$ AMARANTE, P. D. de C., (coordenador), Loucos pela vida: a trajetória da reforma psiquiátrica no Brasil. Rio de Janeiro, FIOCRUZ, 1995, p. 82.

${ }^{16}$ O Programa de Volta para Casa foi instituído pelo Presidente Lula, por meio da assinatura da Lei Federal 10.708 de 31 de julho de 2003 e dispõe sobre a regulamentação do auxílio-reabilitação picossocial a pacientes que tenham permanecido em longas internações psiquiátricas. O objetivo deste programa é contribuir efetivamente para o processo de inserção social dessas pessoas, incentivando a organização de uma rede ampla e diversificada de recursos assistenciais e de cuidados, facilitadora do convívio social, capaz de assegurar o bem-estar global e estimular o exercício pleno de seus direitos civis, políticos e de cidadania. Além disso, o "De Volta para Casa" atende ao disposto na Lei 10.216 que determina que os pacientes longamente internados ou para os quais se caracteriza a situação de grave dependência institucional, sejam objeto de política específica de alta planejada e reabilitação psicossocial assistida. Em parceria com a Caixa Econômica Federal, o programa conta hoje com mais de 2600 beneficiários em todo o território nacional, os 


\section{0 Trilema de Fries}

Ao confrontar Kraft, Quine e Popper em alguns de seus textos, é possível tecer breves considerações sobre os enunciados observacionais, sentenças protocolares e o denominado holismo moderado de Quine. Assim, ao ingressar em um processo de descoberta das ideias de Quine deparamo-nos com diversos autores que permeiam o seu percurso reflexivo sobre o empirismo nas ciências naturais e seu processo de construção do objeto científico. Os autores como Kraft, Quine e Popper questionam a questão/relevância do empirismo nas ciências, sendo cada um a sua maneira. Na obra Epistemologia, semântica e ontologia, STEIN, aborda o sistema de ideias de Van Orman Quine em diversos aspectos, contudo nestas breves considerações destacase seu capítulo que trata de seus enunciados observacionais, a partir de sua visão holística e questões se impõem para reflexão no que se refere a qual seria a unidade mínima de significação, ou seja, qual deve ser a abrangência de um sistema lingüistico para que esse tenha a capacidade de 'significar' autonomamente. Devemos observar a ciência em sua totalidade como "o todo da significância empírica"? Ou podemos nos restringir os ramos da ciência para delimitar um sistema significativo? "O todo da ciência é a unidade de significação empírica"17.

A questão que envolve a procura do detalhamento da 'unidade de significado empírica' assevera seu objetivo de pensar sobre a terceira grande mudança no empirismo nos dois últimos séculos, nesse sentido vem corroborar a lição de Stein: foi à percepção de que o veículo da significação empírica não é nem a palavra, nem a frase, e sim uma teoria como um todo. Essa mudança trouxe consigo a interrogação acerca da extensão de um sistema teórico que tenha uma significação independente ${ }^{18}$. E, sobre a reflexão de Popper no quanto às percepções sensórias que nos levam a "aceitar" determinada lógica indutiva, sendo que o autor alerta para o risco da confusão entre a lógica e a psicologia com base nos enunciados da experiência e de sua aceitação dogmática no plano da ciência:

quais recebem mensalmente em suas próprias contas bancárias o valor de $R \$ 240,00$. Em conjunto com o Programa de Redução de Leitos Hospitalares de longa permanência e os Serviços Residenciais Terapêuticos, o Programa de Volta para Casa forma o tripé essencial para o efetivo processo de desinstitucionalização e resgate da cidadania das pessoas acometidas por transtornos mentais submetidas à privação da liberdade nos hospitais psiquiátricos brasileiros. O auxílio-reabilitação psicossocial, instituído pelo Programa de Volta para Casa, também tem um caráter indenizatório àqueles que, por falta de alternativas, foram submetidos a tratamentos aviltantes e privados de seus direitos básicos de cidadania. Disponível em: www.ccs.saude.gov.br/VPC/programa.html, acesso em 25 de Maio de 2013.

${ }^{17}$ STEIN, Sofia Inês Albornoz. Van Orman Quine. Epistemologia, semântica e ontologia. p. 39.

${ }^{18}$ STEIN, Sofia Inês Albornoz. Van Orman Quine. Epistemologia, semântica e ontologia, p. 39. 
A doutrina segundo a qual as ciências empíricas são reduzíveis a percepções sensórias e, conseqüentemente, as nossas experiências, é por muitos aceita como óbvia. Todavia, essa doutrina é acolhida ou rejeitada na dependência de aceitarmos ou não a Lógica Indutiva; aqui a rejeitamos, porque rejeitamos a Lógica Indutiva. Não desejo negar a existência de um grão de verdade na concepção de que a Matemática e a Lógica se alicerçam no pensamento, ao passo que as ciências factuais se fundamentam em percepções sensórias. $\mathbf{O}$ que há de verdadeiro nessa concepção tem, não obstante, pouca relação com o problema epistemológico ${ }^{19}$. (grifo nosso)

Ao longo do texto, Stein aduz que de acordo com Quine todas as ciências particulares estão de certo modo interligadas semanticamente, sendo que considerar tais teorias utilizadas como portadoras de conteúdos empíricos independentes e, deste modo, seria equívoco acreditar que nenhum enunciado isolado possui conteúdo empírico independente. Neste sentido, podemos identificar os enunciados cujo grau de observacionalidade permite decidir sobre sua verdade ou falsidade dos fatos e orações. E, esse é um dos critérios apresentados por Quine para identificar os enunciados por ele denominados observacionais. Se observarmos a linguagem como um todo em movimento, em cuja periferia se encontra os enunciados observacionais que vão se enraizando nos enunciados teóricos, poderemos compreender o holismo de Quine ${ }^{20}$.

O empirismo é utilizado como método absoluto pelo Dr. Bacamarte começa se destacar quando passa a separar seus pacientes na Casa Verde de modo a iniciar uma espécie de taxonomia que lhe garantisse uma melhor condição de analise sobre as patologias:

\footnotetext{
"Uma vez desonerado da administração, o alienista procedeu a uma vasta qualificação dos seus enfermos. Dividiu-os primeiramente em duas classes principais: os furiosos e os mansos; daí passou às subclasses, monomanias, delírios, alucinações diversas. Isto feito começou um estudo aturado e contínuo; analisava os hábitos de cada louco, as horas de acesso, as aversões, as simpatias, as palavras, os gestos, as tendências; inquiria da vida dos enfermos, profissão, costumes, circunstâncias da revelação mórbida, acidentes da infância e da mocidade, doenças de outra espécie, antecedentes na família, uma devassa, enfim, como a não faria o mais atilado corregedor. $^{21 "}$ (grifo nosso)
}

Em Kraft há uma descrição dos pressupostos e referências no movimento intelectual que incorporou teóricos das mais variadas áreas desde o inicio do século XX e, em sua obra El Circulo

\footnotetext{
${ }^{19}$ POPPER, Karl. Lógica da Pesquisa Cientifica. p. 99.

${ }^{20}$ STEIN, Sofia Inês Albornoz. Op. cit, p 39.

${ }^{21}$ MACHADO DE ASSIS, Joaquim Maria. O alienista. Porto Alegre: LPM, 2010. p. 22. 
de Viena, o desenvolvimento e relevância dos fundamentos dos por ele denominados enunciados verificadores é abordado da seguinte maneira:

Se define negativamente una proposición atómica singular que, a su vez, no contiene los conceptos ((todos)) o algunos)).(...) Ahora bien, Wittgenstein aportó la: idea nueva e importante de que la verdad de las preposiciones depende únicamente de la verdad de las preposiciones simples, que son sus partes; es una funcíon de verdad de estas. (...) La condición de verdad de los enunciados que tienen la forma má sencilia puede formularse directamente: son verdaderos cuando ai objeto designado mediante ei nombre le corresponde efectivamente la propiedad o relación designada mediante el predicado. Las condiciones de verdad de las otras formas de enunciados, las compuestas de elementos, se determinan indirectamente. (...) una implicación y de una negación con la verdad y la falsedad de lãs proposiciones singulares como consecuencia del significado de «y», «o», '<si», «no», de las «constantes lógicas. ${ }^{22}$ (grifo nosso)

Outro tema que ocupa a reflexão dos autores Quine e Popper $^{23}$ é a influência do pensamento dogmático na reflexão filosófica. Cada um a sua maneira desenvolve uma empreitada questionando e opondo-se ao que identifica em diversos momentos como sendo uma espécie de dogmática no pensamento científico, uma vez que em algumas situações supervaloriza o empirismo, e em outras relativiza-o. Com peculiaridades em sua racionalidade lógica aponta limites e imperfeições nos elementos que refutam dogmáticos e, deste modo, compreende que será dogmático o pensamento que leve a uma regressão infinita.

E, sobre a tarefa de evitarmos o perigo do dogmatismo e possibilidade de sua regressão infinita, Popper assevera que aparentemente não restará outro recurso que não o psicologismo (o que se constituiria em equívoco):

doutrina de acordo com a qual enunciados podem encontrar justificação não apenas em enunciados, mas também na experiência perceptual. Diante desse trilema - dogmatismo vs. regressão infinita vs. psicologismo - Fries, e com ele quase todos os epistemologistas que desejavam explicar nosso conhecimento empírico, optaram pelo psicologismo. Na experiência sensória, ensinou ele, encontramos "conhecimento imediato": através desse conhecimento imediato podemos justificar nosso "conhecimento mediato" conhecimento expresso no simbolismo de alguma linguagem. E

${ }^{22}$ KRAFT, Victor. El Circulo de Viena. p.131-2.

${ }^{23}$ POPPER, Karl. Lógica da Pesquisa Cientifica, p. 119. Em Popper aceitá-los é parte da aplicação de um sistema teorético; e só essa aplicação torna possíveis subseqüentes aplicações do sistema teorético: $A$ base empírica da ciência objetiva nada tem, portanto de "absoluto" A ciência repousa em pedra firme. A estrutura de suas teorias levanta-se, por assim dizer, num pântano. Semelha-se a um edifício construído sobre pilares. Os pilares são enterrados no pântano, mas não em qualquer base natural ou dada. Se deixarmos de enterrar mais profundamente esses pilares, não o fazemos por termos alcançado terreno firme. Simplesmente nos detemos quando achamos que os pilares estão suficientemente assentados para sustentar a estrutura - pelo menos por algum tempo. 
esse conhecimento mediato inclui, naturalmente, os enunciados da Ciência(grifo nosso) ${ }^{24}$.

Acerca da verificação da ciência resgatamos a visão de Popper sobre a suposta resolução do Trilema de Fries $^{25}$, resultando no fato de que toda prova (ou seria evidência?) de uma teoria, resulta de sua corroboração (justificação, legitimação) ou em construção de informações imprecisas e erradas que se manifeste e forme algum enunciado básico que decidimos anuir. Sobre a (im)possibilidade de decidirmos e não aceitarmos esta ou aquela compreensão a respeito de um enunciado básico, a prova terá conduzido a nada, uma vez que as experiências podem justificar uma possibilidade de decisão sobre um enunciado.

Ainda sobre o tema que reflete uma cizânia em torno do enunciado básico e sua justificação Popper leciona que:

\begin{abstract}
Qual a nossa posição agora, com respeito ao trilema de Fries, escolha entre dogmatismo, regressão infinita ou psicologismo? (Cf. seção 2.5.) Os enunciados básicos em que nos detemos que decidimos aceitar como satisfatórios e como suficientemente aprovados pelas provas, têm, reconhecidamente, o caráter de dogmas, mas apenas na medida em que desistirmos de justificá-los por argumentos outros (ou por outras provas). Essa espécie de dogmatismo é, todavia, inócua, pois que, surgida à necessidade, os enunciados podem ser facilmente submetidos a provas complementares. Admito, em princípio, que isso torna infinita a cadeia de deduções. Contudo, essa espécie de "regras (2) são infinita" é também inócua, uma vez que, em nossa teoria, não se coloca empenho em tentar provar, por meio dela, qualquer enunciado. Finalmente, no que concerne ao psicologismo, admito que a decisão de aceitar um enunciado básico e dá-lo por satisfatório está causalmente relacionada com nossas experiências em especial, a nossas experiências perceptuais. ${ }^{26}$ (grifo nosso)
\end{abstract}

A situação real difere muito da visualizada pelo empirista ingênuo ou pelo adepto da lógica indutiva, de caráter limitado, no qual acredita que eles partam da reunião e reconciliação de nossas experiências, in casu, continuidade de um sistema de crenças que se auto-justificam ou se auto-legitimam indefinidamente, dessa maneira ascendemos na escala da ciência, eis que não

\footnotetext{
${ }^{24}$ POPPER, Karl. Lógica da Pesquisa Cientifica, p. 100.

${ }^{25}$ Ibid., p. 111-2. É muito fácil perceber que desse modo chegamos a um processo segundo o qual só nos detemos numa espécie de enunciado particularmente suscetível de prova. Isso quer dizer que nos estamos detendo em enunciados acerca de cuja aceitação ou rejeição é de esperar que os vários investigadores se ponham de acordo. (...) Caso, algum dia, não seja mais possível, aos observadores científicos, chegar a um acordo acerca de enunciados básicos, equivaleria isso a uma falha da linguagem como veículo de comunicação universal. (...) Assim como uma prova lógica assumiu feição satisfatória, depois de terminado o trabalho difícil, proporcionando fácil verificação, assim também a ciência, depois de ter realizado sua tarefa de dedução ou de explicação, leva a enunciados básicos facilmente passíveis de teste. Enunciados a propósito de experiências pessoais - isto é, sentenças protocolares - é claro, não se filiam a essa espécie; dessa forma, não se mostram adequados para servir como enunciados em que nos detenhamos. (grifo nosso)

${ }^{26}$ POPPER, Karl Lógica da Pesquisa Cientifica, p. 112-3. 
pode ser respondida por qualquer teoria falseável, portanto a "metafísica", consoante a percepção de Quine.

Ao longo do texto Machado de Assis dialoga a respeito dos indícios que levam o alienista a concluir pela loucura de um ou outro habitante e a lógica que o leva a na diferença do padrão de comportamento em restante a coletividade a declarar a loucura e o eventual recolhimento a Casa Verde a fim de proceder ao estudo e a sua possível cura. Tal fato o levará a confrontar-se com o poder instituído, Câmara de Vereadores, e os cidadãos que se sentem corretamente ameaçados pelo médico. Uma rebelião se instaura e chegam às portas a Casa Verde e a cidade:

\begin{abstract}
"os amigos à demolição da Casa Verde; poucas vozes e frouxas the responderam. Foi nesse momento decisivo que o barbeiro sentiu despontar em si a ambição do governo; pareceu-lhe então que, demolindo a Casa Verde, e derrocando a influência do alienista, chegaria a apoderar-se da Câmara, dominar as demais autoridades e constituir-se senhor de Itaguaí. Desde alguns anos que ele forcejava por ver o seu nome incluído nos pelouros para o sorteio dos vereadores, mas era recusado por não ter uma posição compatível com tão grande cargo. A ocasião era agora ou nunca. Demais fora tão longe na arruaça, que a derrota seria a prisão, ou talvez a forca, ou o degredo. Infelizmente, a resposta do alienista diminuíra o furor. (...) -Não nos dispersaremos. Se quereis os nossos cadáveres, podeis tomá-los; mas só os cadáveres; não levareis a nossa honra, o nosso crédito, os nossos direitos, e com eles a salvação de Itaguaí. Nada mais imprudente do que essa resposta do barbeiro; e nada mais natural. Era a vertigem das grandes crises $^{27}$." (grifo nosso)
\end{abstract}

A teoria falseável, a partir da experiência sensória propicia explicar como tão freqüentemente alcançamos êxito com as teorias por nós elaboradas - como explicar que existam as denominadas "leis naturais" ${ }^{28}$ que podem caracterizar um sistema rígido de pensamento dogmático permeado por um positivismo lógico que está contido, segundo Popper no psicologismo, entre outros. Quine trilhou o caminho da lógica e do empirismo na construção de uma ontologia onde nenhuma entidade deve existir sem identidade a entificação da palavra se torna pragmaticamente inútil e criadora de problemas.

\title{
4. Experiência, Dogmatismo e Empirismo.
}

A experiência como elemento fundamental do empirismo é visualizado de modo distinto pelos autores e, neste sentido, o caminho diverso percorreu Popper acreditando que nas epistemologias do sensualismo e do positivismo, dá-se por admitido que os enunciados científicos

\footnotetext{
${ }^{27}$ MACHADO DE ASSIS, Joaquim Maria. O alienista. Porto Alegre: LPM, 2010. p. 53-4.

${ }^{28}$ POPPER, Karl. Lógica da Pesquisa Cientifica, p. 114. 
empíricos "falam de nossas experiências", e destaca o fato que podemos atingir qualquer conhecimento dos fatos por meio da percepção sensória constitui-se em contribuição de Popper ${ }^{29}$ que a caracteriza como fonte de conhecimento.

Nesse prisma, em Popper a teoria empírica é privilegiada ao longo de suas investigações como elemento fundamental de corroboração científica, veja as suas palavras: apóia-se nos problemas da indução e dos universais: efetivamente, não há como emitir um enunciado científico sem ultrapassar, de muito, aquilo que pode ser conhecido de maneira incontestável, "com base na experiência imediata" ${ }^{30}$. Em Quine verifica-se uma percepção no que tange os enunciados, uma vez que nos leva a conclusão de que o importante é a constatação de que não é possível apontar exatamente qual ou quais enunciados são afetados pela mudança dos valores de verdade de determinados enunciados observacionais, eis que podemos imaginar diferentes hipóteses científicas explicando os mesmos fatos, o que significa que os enunciados teóricos não são redutiveis a um conjunto de enunciados observacionais ${ }^{31}$.

O processo dogmático reflexivo que o alienista adota na sua busca humanista pela cura da loucura evidencia-se em relação a uma espécie de indiferença que manifesta em relação a mulher e, de certo modo, está presente quando a mesma prepara-se para sua viagem ao Rio de Janeiro quando Bacamarte dará curso a uma fase mais ousada de transformação na Casa Verde:

\footnotetext{
"As despedidas foram tristes para todos, menos para o alienista. Conquanto as lágrimas de D. Evarista fossem abundantes e sinceras, não chegaram a abalá-lo. Homem de ciência, e só de ciência, nada o consternava fora da ciência; e se alguma coisa o preocupava naquela ocasião, se ele deixava correr pela multidão um olhar inquieto e policial, não era outra coisa mais do que a idéia de que algum demente podia achar-se ali misturado com a gente de juízo ${ }^{32 "}$.
}

\footnotetext{
${ }^{29}$ Ibid, p. 100. Assim, a experiência perceptual deve constituir-se na única "fonte do conhecimento" de todas as ciências empíricas. Tudo o que sabemos acerca do mundo dos fatos deve, pois, ser suscetível de expressão sob a forma de enunciados acerca de nossas experiências. Só podemos chegar à conclusão de que esta mesa é azul ou verde consultando nossa experiência sensorial. Pelo imediato sentimento de conviç̧ão que ela nos transmite, podemos distinguir o enunciado verdadeiro, aquele cujos termos estão em concordância com a experiência, do enunciado falso, aquele cujos termos não concordam com a experiência. A Ciência não passa de uma tentativa de classificar e descrever esse conhecimento perceptual, essas experiências imediatas, de cuja verdade não podemos duvidar; ela é a apresentação sistemática de nossas convicções imediatas de cuja verdade não podemos duvidar; ela é a apresentação sistemática de nossas convicções imediatas. (grifo nosso).

${ }^{30}$ Ibid., p. 101.

${ }^{31}$ STEIN, Sofia Inês Albornoz. Van Orman Quine. Epistemologia, semântica e ontologia. p. 40.

32 MACHADO DE ASSIS, Joaquim Maria. O alienista. Porto Alegre: LPM, 2010. p. 36.
} 
Retornando ao pensamento de Kraft, em sua obra El Circulo de Viena, de certo modo a redução se facilita mediante uma espécie de genealogia dos conceitos, através da qual são reduzidas as relações de vivências (experiências), tal como se apresenta no sistema de constituição de Carnap, onde se aproximam as teorias: empirista do significado, a dos conceitos e dos enunciados. E, por essa razão tornam-se especial retomarmos no autor os seus enunciados gerais e as preposições elementares que recebem a seguinte abordagem:

La verdad de un enunciado general es una funcion de la verdad de todos los enunciados singulares que caen bajo este enunciado general y que están determinados por una condición de verdad directa. Por tanto, un enunciado general tiene que poder formarse como una conyunción de enunciados simples (...) «proposiciones elementales. Son éstas proposiciones que pueden ser comparadas imediatamente com la realidad, es decir, con lo dado em las vivencias. Tiene que haber tales preposiciones, ya que de lo contrario el lenguage no tendria relacion com la realidade. Todos los enunciados que no son ellos mismos proposiciones elementales tienen que ser funciones de verdade de preposiciones elementales. ${ }^{33}$ (grifo nosso)

Com maior intensidade Quine realiza sua crítica à convencional tradição empirista e indica alguns de seus argumentos com intuito de justificar o seu modelo de holismo moderado, pois assume posição crítica frente à tradição e aos dogmas empiristas da distinção analítico/sintético e do reducionismo. Quine tem de enfrentar duas questões centrais da linguagem: a) como explicar o funcionamento da linguagem, sem utilizar para tanto nenhuma linguagem filosófica com termos intencionais; 2) como explicar a indeterminação do significado dos enunciados teóricos, pois se o significado dos enunciados teóricos fosse determinado, recairíamos na defesa da tese reducionista e, como conseqüência, teria novamente o problema de saber qual é afinal o conteúdo empírico de enunciados como os da matemática. Para sustentar a indeterminação do significado de enunciados teóricos. ${ }^{34} \mathrm{Em}$ Popper tudo é lógica e uma insistente refutação ao que classificava como metafísico.

Em perspectiva distinta, Popper desenvolve uma crítica aproximativa interessante no que se refere às denominadas "sentenças protocololares" que buscam embasar as "modernas" teorias de base empírica de Neurath e Carnap:

Reininger chegou à conclusão de que enunciados só podem ser comparados a enunciados. Segundo ele, a correspondência de um enunciado com um fato nada mais é que a correspondência lógica entre enunciados pertencentes a diferentes níveis de universalidade: é "... a correspondência de enunciados de nível superior com enunciados de conteúdo similar e, em última análise, com enunciados que registram

\footnotetext{
${ }^{33}$ KRAFT, Victor. El circulo de Viena. p. 133.

${ }^{34}$ STEIN, Sofia Inês Albornoz. Van Orman Quine. Epistemologia, semântica e ontologia. p. 40-1. 
experiências"; (estes são, algumas vezes, chamados "enunciados elementares", na terminologia de Reininger). (...) Carnap parte de uma questão algo diversa. Sua tese é a de que todas as investigações filosóficas se referem as "formas de expressão". À lógica da ciência cabe investigar "as formas da linguagem científica". (grifo nosso.) ${ }^{35}$.

Ainda sobre o tema da validade das sentenças protocolares, $\mathrm{Kraft}^{36}$ traz à baila seu debate que diversifica entre sua validade absoluta a sua inexistente relevância para a compreensão da racionalidade do empirismo, com Carnap e Neurath que segundo o autor lhe apresenta como ponto de redução final.

STEIN informa que para responder a tais questões Quine desenvolve seu método naturalista-behaviorista, que procura explicar a fonte do significado de conjuntos de palavras e frases em termos puramente extensionais (conceito fundamental para o autor) e elaborou a tese da indeterminação da tradução, sustentada sobre a tese da inescrutabilidade da referência ${ }^{37}$ de termos observacionais. O holismo moderado é a resposta de Quine a certos princípios fundamentais do positivismo lógico, especialmente à Carnap e produz severa critica certas verdades aceitas pelos empiristas tradicionais e seus seguidores como irrefutáveis, e, afirma que a idéia de que haja uma linha divisória entre enunciados analíticos e sintéticos é um dos mitos criados pelo empirismo e a crença na possibilidade de todos os enunciados das teorias científicas poderem ser reduzidos a enunciados observacionais. ${ }^{38}$

Entretanto, como o próprio Carnap confessa, essa seria apenas o começo de uma construção completa e sistemática da redução desejada, no qual seu aparato utilizado nessa obra provém da Lógica e da Teoria dos Conjuntos, que não seriam consideradas apenas ferramentas necessárias na concretização da empresa empirista, mas também como fazendo parte daquele aspecto da linguagem que não é empírico, porém forma a filosofia de Carnap se insere na chamada "teoria verificacional do significado", que remonta a Peirce e que afirma que o significado de um enunciado depende da possibilidade de este poder ser confirmado ou refutado

\footnotetext{
35 POPPER,Karl. Lógica da Pesquisa Cientifica, p.101-2.

${ }^{36}$ KRAFT, Victor. El circulo de Viena. p. 135. Tales proposiciones protocolarias (enunciados perceptivos) se se consideraron primeramentemente como absolutamente válidas. Son «proposiones que no necessitan confirmación, sirviendo como fundemento para todas las proposiciones restantes de la ciência. Neurath impugnó este carácter de la validez absoluta'. Les proposiciones protocolarias pueden cosiderarse también in válidas en caso necesario, pues nunca estan livres de elaboración, no son más originadas que otras proposiciones empíricas, son tan hipotéticas como y, por tanto, son corregibles. Los enunciados no pueden compararse en modo a1guno con lo dado, con vivencias, con algo extralinguístico. Los enunciados solo pueden compararse con enunciados. Carnap se adhirio también a esta opinión de Neurath. Las proposiclones protocolarias no tienen ningún rango privilegiado sobre las otras proposiciones. Ciertas proposciones protocolarias, esto es, como puntos finales de reducción..(grifo nosso)

37 STEIN, Sofia Inês Albornoz. A dimensão metafísica da inescrutabilidade da referência. FILOSOFIA: UNISINOS, maio/ago 2006. Ver analise desenvolvida pela professora Dra. Sofia Stein sobvre a tese de Quine.

${ }^{38}$ STEIN, Sofia Inês Albornoz. Van Orman Quine. Epistemologia, semântica e ontologia. p. 41.
} 
pela experiência imediata. Popper se opõe a ideia de Carnap uma vez que as sentenças protocolares não necessitam de confirmação. Ainda sobre o tema da crítica que Kraft traz em relação a alguns limites teóricos do Circulo de Viena importa destacar sua posição sobre os enunciados $^{39}$ de vivencias típicos do empirismo original ${ }^{40}$. De outra maneira, em Popper verificamos que: Neurath não tenta solucionar o problema da demarcação, sua idéia de sentenças protocolares e que parece mero resíduo - lembrança remanescente da concepção tradicional, defensora de que a Ciência se origina da percepção ${ }^{41}$. Diversamente, de uma compreensão de trabalho epistemológico conceitual tem como interesse específico o esclarecimento de significados por meio da tradução de enunciados da ciência a enunciados primitivos. A não da verdade destas pode ser verificada pela experiência por meio dos enunciados empíricos deduzidos dela.

O trabalho epistemológico conceitual é chamado por Quine de reducionismo radical, por sustentar que todo enunciado significativo possa ser traduzido para um enunciado, verdadeiro ou falso, sobre a experiência imediata. Portanto, procura Quine demonstrar que eventos empíricos têm possibilidades em sua visão holística:

Apesar de Quine concordar com as duas teses básicas do empirismo, quais sejam: (a) de que toda a evidência de que a ciência dispõe é evidência sensorial e (b) de que qualquer processo de inculcar significados a palavras terá de repousar numa evidência sensorial, ele critica o empirismo clássico por sustentar o mito de que para todo enunciado sintético "[...] existe um domínio único de eventos sensoriais possíveis, tais que a ocorrência de qualquer um deles contribuiria para a probabilidad da verdade do enunciado [...j" (Quine 1980a: 245). Em termos gerais, sua posição é de que eventos empíricos podem confirmar uma teoria, ou as previsões de uma teoria,

\footnotetext{
${ }^{39}$ KRAFT, Victor. El circulo de Viena. p. 146-7. Hay que abandonar la concepción de los enunciados sobre vivencias como fundamentos del conocimiento, en ya forma en que predominaba en el empirismo anterior y a ia que Popper combate como «inductiyismo». De acuerdo con elia, los enunciados sobre vivencias se hailan iógicamente ai comienzo y ei conocimiento empírico y las proposiciones generales se obtienen por su ordenacián y síntesis en ia inducción. Pero la induo. ción sólo puede justificarse como procedimiento I6gico riguroso si está dada una premisa de la máxima generalidad que permita la deducción lógica de proposiciones generales a partir de ias particulares, si está dado un principio de inducción. Este principio tendria que ser un enunciado general sintético sobre la realidad, sobre ia uniformidad dei acontecer natural.. (grifo nosso)

${ }^{40}$ Ibid., p. 41. A forma a criar a possibilidade de confirmar-se ou refutar-se uma teoria diretamente mediante observação empírica que oportunizou à Quine ingressar teoricamente nas questões investigadas pelo empirismo primeiramente devido ao seu interesse por questões lógicas e principalmente ao seu interesse relativo à tentativa de reduzir a matemática à lógica. Acompanhou durante seus estudos a trajetória teórica da tradição filosófica do Círculo de Viena, concentrando sua atenção na obra de Carnap (primeira real tentativa de concretizar o sonho empirista de reduzir os enunciados das teorias cientificas em enunciados cujo conteúdo refere-se imediatamente à experiência sensorial. (grifo nosso)
}

${ }^{41}$ POPPER, Karl. Lógica da Pesquisa Cientifica, p. 99. 
porém não confirmam um único enunciado desta teoria, a não ser no caso de enunciados observacionais. ${ }^{42}$ (grifo nosso)

A simultânea defesa e crítica ao empirismo feita por Quine, desemboca na posição filosófica holista, consistindo basicamente em que os enunciados da ciência não podem ser submetidos à avaliação empírica isoladamente, mas apenas em conjuntos "mais ou menos amplos". E, nesse sentido Quine valoriza o aspecto essencial dos enunciados observacionais, a característica deles de introduzirem 'conteúdo empírico' ou 'significado' na linguagem, por meio da referência ao mundo, o que os determina enquanto tais sem o fundamentalismo de autores já citados. A sentença observacional é elemento estruturante da semântica. Ainda, em sua abordagem percebemos que ocorre uma espécie de análise 'genética' da linguagem, quando procura entender os mecanismos de aprendizado da linguagem, portanto também a capacidade humana de aquisição de uma linguagem complexa.

Em Popper, por seu turno, verificamos certa instabilidade na afirmação da objetividade da base empírica ${ }^{43}$ frente aos diversos dilemas apresentados pelo próprio autor, sobre o fato de a lógica permitir em nome da ciência manipulações mentais. Entretanto, em relação ao denominado 'novo empirismo', Quine constrói não necessariamente uma correspondência determinada entre mundo e linguagem e adentra num cenário muito interessante das interrelações entre os enunciados e determina o todo, que, por sua vez ajusta-se às modificações dos valores-verdade dos enunciados observacionais da periferia.

Quine nega, sustentado nas muitas tentativas feitas e fracassadas e na história da ciência, que se possa traduzir os enunciados científicos em enunciados sobre a experiência imediata, portanto, que possa haver um reducionismo. Em substituição ao reducionismo, Quine propõe uma visão holista das teorias científicas, assim como também de todos os diversos

\footnotetext{
${ }^{42}$ STEIN, Sofia Inês Albornoz. Van Orman Quine. Epistemologia, semântica e ontologia. p. 42.

${ }^{43}$ POPPER, Karl. Lógica da Pesquisa Cientifica, p. 104. "(como diz Hahn) só tomamos consciência dos fatos pela observação". Mas essa consciência, esse nosso conhecimento, não justifica nem estabelece a verdade de qualquer enunciado. (...) Contudo, há não muito tempo sustentava-se que a Lógica era uma Ciência que manipula os processos mentais e suas leis as leis de nosso pensamento. Sob esse prisma, não se podia encontrar outra justificação para a Lógica, a não ser na alegação de que não nos é dado pensar de outra maneira. Uma inferência lógica parecia justificar-se pelo fato de ser sentida como uma necessidade de pensamento, um sentimento de que sómos compelidos a pensar ao longo de certas linhas. No campo da Lógica, talvez se possa dizer que essa espécie de psicologismo é, hoje, coisa do passado. Ninguém sonharia em justificar a validade de uma inferência lógica, ou em defendê-la contra possíveis dúvidas, escrevendo ao lado, na margem, a seguinte sentença protocolar "protocolo: revendo essa cadeia de inferências, no dia de hoje, experimentei forte sensação de convicção". (...) A posição torna-se diferente quando passamos aos enunciados empíricos da Ciência. Aqui, todos acreditam que esses enunciados, tal como a percepção, fundamentam-se em experiências; ou, passando para o modo formal de expressão, em sentenças protocolares. "A maioria reconhecerá que qualquer tentativa de alicerçar os enunciados lógicos em sentenças protocolares traduz inclinação para o psicologismo." (grifo nosso)
} 
universos lingüísticos. Os enunciados observacionais que fazem parte de determinada teoria científica não estão ligados a nenhum enunciado teórico específico, isto é, caso sejam considerados falsos, sua falsidade não implicará a falsidade de alguma ou alguns enunciados teóricos específicos; é o todo da teoria que sofrerá os efeitos da negação do enunciado observacional $^{44}$. (grifo nosso)

Entretanto, critica a pretensão empirista que supõe a possibilidade de verificação de cada enunciado teórico individual de um universo lingüístico, seja mediante experiência imediata, seja mediante uma tradução que leve a enunciados sobre a experiência imediata. Introduzindo a noção de enunciado observacional, Quine quer evitar a queda em um ceticismo com relação à verdade, que seria fruto da frustração de não poder responder às questões centrais do empirismo lógico.

A política sempre esteve próxima da ciência, da saúde e da transformação das condições a realidade do ponto de vista institucional e, na obra literária em análise, esse aspecto assume visibilidade no curso da Revolução de Itaguaí cujo líder fundamental foi o barbeiro:

"O momento foi indescritível. A multidão urrou furiosa; alguns, trepando às janelas das casas, ou correndo pela rua fora, conseguiram escapar; mas a maioria ficou, bufando de cólera, indignada, animada pela exortação do barbeiro. A derrota dos Canjicas estava iminente, quando um terço dos dragões qualquer que fosse o motivo, as crônicas não o declaram - passou subitamente para o lado da rebelião. Este inesperado reforço deu alma aos Canjicas, ao mesmo tempo que lançou o desânimo às fileiras da legalidade. Os soldados fiéis não tiveram coragem de atacar os seus próprios camaradas, e, um a um, foram passando para eles, de modo que, ao cabo de alguns minutos, o aspecto das coisas era totalmente outro. $O$ capitão estava de um lado, com alguma gente, contra uma massa compacta que o ameaçava de morte. Não teve remédio, declarou-se vencido e entregou a espada ao barbeiro. (...) A revolução triunfante não perdeu um só minuto; recolheu os feridos às casas próximas, e guiou para a Câmara. Povo e tropa fraternizavam, davam vivas a el-rei, ao vice-rei, a Itaguaí, ao 'ilustre Porfirio". (grifo nosso)

Porém, apesar de querer conservar-se nos limites da tradição empirista, parece sempre resvalar para além dela e posicionar-se em um plano ainda não totalmente determinado da investigação filosófica. As condições foram modificadas e a teoria cientifica adotada será transformada ou iniciará reflexão a fim de justificar a nova realidade observada. Porfírio venceu a institucional idade, garantiu legitimidade social e, em seguida, foi compor com o discurso cientifico dominante ao qual se opunha "a princípio" irreconciliavelmente.

\footnotetext{
${ }^{44}$ STEIN, Sofia Inês Albornoz. Van Orman Quine. Epistemologia, semântica e ontologia. p. 43. 


\section{Enunciados Observacionais}

Em primeiro lugar, a mudança do valor de verdade de determinados enunciados observacionais implica necessariamente uma mudança nas relações internas entre os enunciados teóricos e observacionais de um corpo lingüístico. Não implica, contudo, diretamente a mudança do valor de verdade de um enunciado isolado no interior deste corpo. De certo modo, desenvolvem uma reflexão sobre a entificação que se torna inútil e criadora de problemas e, portanto, a revisão de enunciados com base em experiências 'recalcitrantes' permanece possível, inclusive porque, para Quine, todo enunciado, por mais afastado da experiência que esteja, está contaminado por algum tipo de conteúdo empírico ${ }^{45}$.

Ainda sobre o tema dos enunciados básicos ${ }^{46}$ relembremos Popper. Já nos textos de Quine, segundo a autora, utilizam um vocabulário diversificado para falar de um 'universo semântico', ou seja, do um conjunto de enunciados que formam uma unidade significativa ${ }^{47}$. Encontramos denominações como 'sistema teórico', 'teoria científica', 'linguagem', 'sistema conceitual', etc. A primeira vista, parece aceitável usar de forma permutável as expressões 'teoria' e a linguagem compartilhada socialmente:

\footnotetext{
"superar o empirismo lógico (um empirismo sem dogmas). Porem mais do que um critica do empirismo contemporâneo, Quine é um filosofo preocupado em resolver problemas deixados em aberto pelos empiristas, principalmente pelos empiristas lógicos. Por fim Quine mantém viva a tese do empirismo, mas, também, qual é a melhor base empírica para ciência. e, nessa esteira Davidson, entende que podem separa esquemas conceituais ou teorias daquilo que da conteúdo a essas teorias (a ideia é, então, a de que algo é uma linguagem, e associada com um esquema conceitual. Assim, segundo Davidson, continua sendo o objetivo de Quine mostrar como se relaciona uma teoria científica ou um esquema conceitual com a experiência ou com aquilo que decidamos chamar de experiência" ${ }^{48}$ (grifo nosso)
}

\footnotetext{
${ }^{45}$ STEIN, Sofia Inês Albornoz. Van Orman Quine. Epistemologia, semântica e ontologia, p. 40.

${ }^{46}$ POPPER, Karl. Lógica da Pesquisa Cientifica, p. 107-8. Os enunciados básicos, conseqüentemente, devem satisfazer as seguintes condições: (a) De um enunciado universal, desacompanhado de condições iniciais, não se pode deduzir um enunciado básico. Por outro lado, (b) pode haver contradição recíproca entre um enunciado universal e um enunciado básico. A condição (b) somente estará satisfeita se for possível deduzir a negação de um enunciado básico da teoria que ele contradiz. Dessa condição, e da condição (a), segue-se que um enunciado básico deve ter uma forma lógica tal que sua negação não possa, por seu turno, constituir-se em enunciado básico. (...) Já deparamos com enunciados cuja forma lógica difere da forma de suas negações. Eram os enunciados universais e os enunciados existenciais: eles são negações um do outro e diferem em sua forma lógica. (grifo nosso)

${ }^{47}$ STEIN, Sofia Inês Albornoz. Van Orman Quine. Epistemologia, semântica e ontologia. p. 43.

48 Ibid., p. 45-6. 
Popper $^{49}$ ao manifestar-se sobre a ciência da lógica e as sentenças protocolares

lembrando Carnap e Reninger esclarece de modo bem especifico que:

Diz ele que as sentenças da Ciência são submetidas a prova "através do auxíljo de sentenças protocolares". (...) no modo ordinário, "material" da expressão - que as sentenças protocolares referem-se ao "dado": aos dados sensoriais. Descrevem-nas (como diz o próprio Carnap) "os conteúdos da experiência imediata, ou os fenômenos; e, assim, os fatos mais simples suscetíveis de conhecimento". Isso mostra, de maneira suficientemente clara, que a teoria das sentenças protocolares não passa de psicologismo traduzido no modo formal de expressão. Coisa muito semelhante pode ser afirmada acerca da concepção de Neurath: quer ele que, nas sentenças protocolares, palavras tais como "perceber", "ver", etc., devam ocorrer acompanhadas do nome completo do autor da sentença protocolar. Sentenças protocolares, como a expressão indica, devem ser registros ou protocolos de observações imediatas ou de percepções.(..) Tal como Reininger, Neurath sustenta que os enunciados perceptuais que registram experiências - isto é, as "sentenças protocolares" - não são irrevocáveis, podendo, por vezes, admitir rejeição. ${ }^{50}$ (grifo nosso)

Popper destaca a forma da doutrina de Neurath, vindo compreender que as sentenças protocolares não são invioláveis, o que corresponde a um grande avanço, no entanto, desconsiderada a substituição das percepções por enunciados-percepção, a doutrina de que as sentenças protocolares: admitem revisão é seu único progresso relativamente à teoria (de Fries) acerca da imediatidade do conhecimento perceptual se acompanhada da ideia de que é: necessário um conjunto de regras para limitar a arbitrariedade na "rejeição" (ou "aceitação") de uma sentença protocolar ${ }^{51}$. Entretanto, Neurath busca afastar-se do dogmatismo e dirige-se no sentido de qualquer sistema arbitrário que tenha pretensão à ciência empírica, e, desta forma, não é muito fácil perceber que parte se reserva às sentenças protocolares no sistema de Neurath. Segundo a concepção anterior de Carnap, o sistema das sentenças protocolares era a pedra de toque com base na qual haveria de ser apreciada toda a asserção de uma Ciência empírica ${ }^{52}$.

Sobre o tema das postulações ${ }^{53}$ no holismo sustentado por Quine verifica-se facilmente um aspecto empirista ao afirmar a necessidade de uma relação de, pelo menos, alguns

\footnotetext{
49 POPPER, Karl. Lógica da Pesquisa Cientifica, p. 102. Ora, essa concepção - com a qual me ponho de acordo leva Carnap (assim como Reininger) a asseverar que não devemos dizer, no campo da Lógica da Ciência, que as sentenças são submetidas prova através da comparação com estados de coisas ou com experiências; só podemos dizer que elas são suscetíveis de prova por meio da comparação com outras sentenças. Carnap, apesar de tudo, está conservando as idéias fundamentais da abordagem psicologística do problema; tudo o que faz é traduzi-las para o "modo formal de expressão".

${ }^{50}$ POPPER, Karl. Lógica da Pesquisa Cientifica, p. 102-3

${ }^{51}$ Ibid., p. 103.

52 Ibid., p. 104.

${ }^{53}$ STEIN, Sofia Inês Albornoz. Van Orman Quine. Epistemologia, semântica e ontologia. p. 46. Se uma teoria quantifica sobre objetos físicos, números, ou conjuntos, o que ela diz sobre essas entidades é verdadeiro contanto a teoria como um todo se adeque à evidência sensorial. Alguém pode ver como, desse ponto de 
enunciados, os observacionais ${ }^{54}$, com a experiência sensível de modo a oportunizar imediata compreensão da realidade verificável frente seus estímulos. E, nesse sentido é necessário que se observe a impressionante analogia entre estímulo como entrada neural global e os elementos básicos de Carnap e suas experiências globais que propiciam a sua relação de similaridade parcial de experiências globais que prosseguem como nossa similaridade parcial de entradas neurais globais. E, ainda sobre os enuciados básicos ${ }^{55}$ é conveniente retomar as lições de Popper. A ligação de qualquer teoria científica ou 'esquema conceitual' com a realidade, segundo Quine, se dá por meio dos enunciados observacionais.

No que tange os Enunciados observacionais, Quine havia definido o stimulus meaning (significado por estímulos) de um enunciado para um sujeito como "a soma das disposições de assentir ou dissentir ao enunciado em resposta a estimulações presentes", e um enunciado de ocasião como aquele ao qual somente se assentiria ou dissentiria se interrogados após uma estimulação apropriada que induzisse a decisão (o veredicto). No centro do pensamento da filosofia de Quine destacamos enunciados observacionais é o portão de ingresso à linguagem e à ciência. ${ }^{56}$

Em sua obra Quine confessa que: o que de fato existe entre enunciados é uma diferença de grau de observacionalidade, pois mesmo os enunciados observacionais podem ter o significado

vista, essas entidades poderiam ser chamadas de postulações. E razoável chamar algo de postulação se pode ser contrastado com algo que não o é. Aqui o algo que não é experiência sensorial pelo menos essa é a idéia (Davidson 1985: 193, tradução nossa). (grifo nosso)

${ }^{54}$ Enunciados observacionais, estritamente falando, são enunciados que aprendemos a usar, ou poderíamos aprender a usar, por condicionamento direto a estimulações simultâneas compartilhadas socialmente. Tipicamente, são enunciados sobre coisas exteriores, não sobre dados sensoriais. O que os faz tão decisivos para julgar teorias científicas é que todos os falantes da linguagem que estão presentes e atentos quando um enunciado observacional é afirmado estão aptos a concordar em assentir a ele. São enunciados que praticamente qualquer um que entenda a linguagem pode verificar ou falsificar por observação imediatamente. (grifo nosso). Ibid., p. 47.

${ }_{55}$ POPPER, Karl. Lógica da Pesquisa Cientifica, p. 110. Poderíamos dizer, com mais precisão, que todo enunciado básico há de ser um enunciado acerca de posições relativas de corpos físicos, ou deve equivaler a algum enunciado básico dessa espécie "mecanicista" ou "materialista". Assim, a acusação de que, apelando para a observabilidade, eu readmiti, clandestinamente, o psicologismo, não teria mais força do que a acusação de que admiti o mecanismo ou o materialismo (...) Digo tudo isso para livrar o termo "observável", na forma em que o emprego, do estigma de psicologismo. Não tenho intenção de definir o termo "observável" ou "evento observável", embora me disponha a elucidá-lo, seja por meio de exemplos mecanicistas ou psicologísticos. Entendo que deva ser introduzido como termo não definido, que se torna suficientemente preciso com o uso: como conceito primitivo, cujo emprego o epistemologista tem de aprender, muito à semelhança de como tem de aprender o termo "símbolo", ou como o físico tem de aprender o termo "ponto-massa". (...) Os enunciados básicos são, portanto, - no modo material da expressão - enunciados asseveradores de que um evento observável está ocorrendo em certa região individual do espaço e do tempo. (grifo nosso)

${ }^{56}$ STEIN, Sofia Inês Albornoz. Van Orman Quine. Epistemologia, semântica e ontologia, p. 48. 
por estímulos para um falante alterado, de uma maneira muito suave, em virtude de informações colaterais, ou seja, apesar delas terem um alto grau de observacionalidade, elas não estão isentas de certa variação em seus significados por estímulos ${ }^{57}$, e em razão dos seus enunciados no que se dedica as critérios a serem implementados também cabe referir: um critério de localização de enunciados observacionais a partir da não-variação dos assentimentos e dissentimentos do falante quando confrontado com certos estímulos; e, de outro lado, um critério de localização por meio da observação do aprendizado do enunciado. Com relação a esses dois critérios, surge a questão de se é possivel: a) o significado por estímulos de um enunciado não variar com informações colaterais; b) um enunciado ser aprendido exclusivamente por ostensão ${ }^{58}$.

Ainda sobre as sentenças observacionais de Quine destacamos:

[...] uma sentença observacional é uma sentença sobre a qual todos os que falam a língua pronunciam o mesmo veredicto, quando é dada a mesma estimulação concomitante. Em termos negativos, uma sentença observacional é uma sentença que não é sensível, no interior da comunidade linguística, a diferenças de experiência passada (Quine 1980b: 166-167). (...) A preocupação central de Quine ao definir enunciados observacionais é justamente patrocinar à ciência uma base empírica para 0 acordo intersubjetivo, portanto não basta definirmos enunciados observacionais para um falante. Nessa última definição, Quine retoma o primeiro critério, que chamei de critério comportamental, já elaborado em Word and Object (1960), que pode ser analisado em duas partes: a) o critério depende da observação do assentimento ou dissentimento dos falantes frente a estímulos; b) o critério depende da constatação da nãoalteração do significado por estímulos por informações colaterais. ${ }^{59}$ (grifo nosso)

Sobre a relevância do enunciado cujo aprendizado se deu ostensivamente é, por sua vez, um enunciado observacional de Quine que nem sempre se torna um enunciado observacional que seja aprendido por todos os membros da comunidade lingüística de modo ostensivo acrescentando à descrição do aprendizado a ressalva de que basta para um enunciado ser observacional, que ele possa ser aprendido por ostensão.

Entretanto, esse último critério criado por Quine, apesar de eliminar o problema em estabelecer uma relação entre as diferentes experiências de estímulos dos diversos falantes de uma comunidade, ignora a possibilidade de interferência de informações colaterais na aplicação de enunciados a situações experienciadas. (...) não saberemos se as informações estocadas no passado pelos indivíduos estão influenciando os seus assentimentos e dissentimentos ao enunciado em estudo. (...) Quine o reformula no seu livro

\footnotetext{
${ }^{57}$ STEIN, Sofia Inês Albornoz. Van Orman Quine. Epistemologia, semântica e ontologia, p. 47.

58 lbid, p. 50.

59 Ibid, p. 50-1. 
Pursuít Oftruth (1990) como a seguir: Eu retenho a minha definição de 1981 de enunciados observacionais para um único falante, e, então, considero um enunciado observacional para um grupo se ele for observacional para cada membro e se cada um concordaria em assentir a ele, ou dissentir, ao testemunhar a ocasião da enunciação (Quine 1990c: 43, tradução nossa) ${ }^{60}$.(grifo nosso)

A dificuldade que os enunciados observacionais evidenciam está presente na obra e Machado de Assis na medida em que o que era diagnostico de sanidade passa a ser de loucura de modo onde o equilíbrio mantido pelo homem (o alienista) é demonstração de inadequação e loucura.

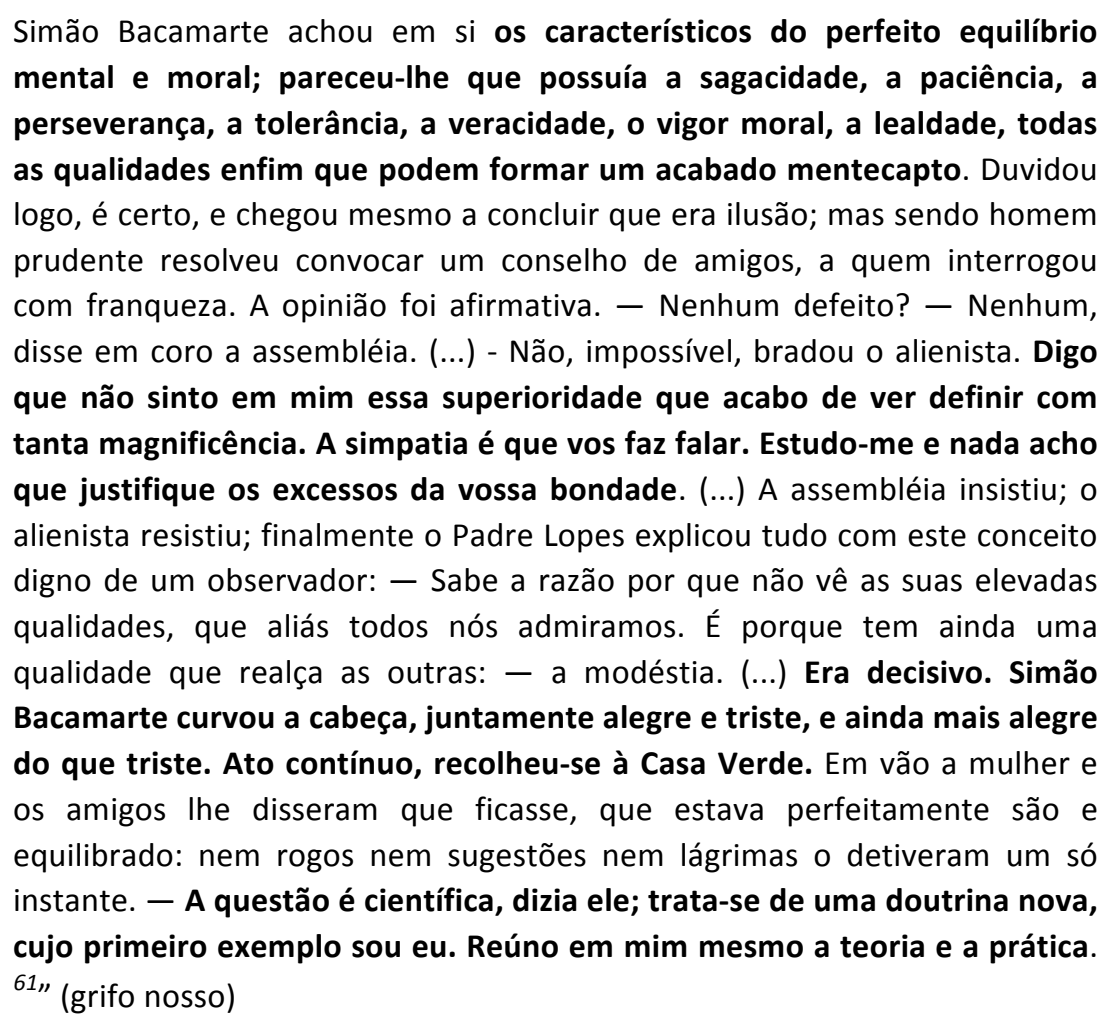

Portanto, os elementos que para uma teoria são concebidos como fundamentais para a melhor descrição do problema e agir de modo a melhor produzir resposta ao problema e observado na metodologia cientifica utilizada por Bacamarte e, certo modo, (des)velado por Porfírio quando recusa a retomar ideias revolucionarias pois já estava conforme a postura cientifica do alienista e é preso (é conduzido novamente a Casa Verde) pelo mesmo em razão de sua oposição a outros suspiros revolucionários e diz: - Preso por ter cão, preso por não ter cão" 62 . $E$, em Quine a virtude de sua reflexão constitui na definição de suas sentenças observacionais a partir de noções de fatos e de significados verificáveis por meio de estímulos (stimulus meaning). Tem por característica sua não modificação em razão da influência de estímulos colaterais, não se

\footnotetext{
${ }^{60}$ STEIN, Sofia Inês Albornoz. Van Orman Quine. Epistemologia, semântica e ontologia, p. 52.

${ }^{61}$ MACHADO DE ASSIS, Joaquim Maria. O alienista. Porto Alegre: LPM, 2010. p. 86-7.

62 Ibid. p. 86-7. 
transformando e indicando que a sentença observacional é de um significado de tipo determinado definível em termos comportamentais. Ainda, sobre o tema destacamos o fato de que pelo seu alto grau de observacionalidade tais sentenças podem tornar realizável a situação de resolução de disputas entre cientistas ${ }^{63}$, uma vez que sem mediação (diálogo) de informações complementares a partir de suas experiências a comunicação não é processada de modo eficiente. Em Quine temos uma visão mais ampla da questão que envolve a realidade empírica de objetos não-observáveis questionando o desenvolvimento da ciência contemporânea e sua dispensabilidade de um discurso sobre a percepção ${ }^{64}$ para o esclarecimento da formação dos objetos das denominadas ciências naturais.

\section{Considerações Finais}

Na obra "O Alienista" de Machado de Assis verificamos que sua busca pela cura da loucura é eivada de sentimento humanista, mas seu método empirista e o dogmatismo representam instabilidade social e cientifica. Seu empirismo se constitui em equívocos lamentáveis e descontrolados que coloca em risco a sociedade (Itaguaí). Sua política de saúde mental acaba se tornando política publica quando a Câmara de Vereadores anui com suas iniciativas e gera insegurança social.

$\mathrm{Na}$ análise do debate sobre a ciência e empirismo, Kraft observa que não é por um convênio arbitrário que se podem aceitar os denominados enunciados de vivência típicos de uma teoria empirista, mas apenas na regularidade com que os fatos vivenciam vão se apresentando na realidade objetiva, bem como podem ser comprados por diversos sujeitos, pois a verificação depende da concordância dos enunciados com sua comprovação. No holismo moderado que é denominado com os Enunciados Observacionais de Quine, o autor verifica a impossibilidade de comparar de forma isolada visando à determinação da verdade ou falsidade de todo enunciado de uma teoria com os dados da experiência, eis que não acredita na possibilidade de determinação do conteúdo empírico isolado da maioria desses enunciados. Há uma clara aproximação entre as sentenças protocolares de Popper e os enunciados observacionais de Quine que ainda acredita na necessidade e possibilidade de relacionar 'alguns' enunciados aos quais denomina observacionais com a experiência.

A sentença observacional de Quine para a comunidade onde uma sentença é observacional destina-se para cada membro da comunidade. Do empirismo Quine absorve, em

${ }^{63}$ STEIN, Sofia Inês Albornoz. A dimensão metafísica da inescrutabilidade da referência. FILOSOFIA: UNISINOS, maio/ago 2006. p. 188.

${ }^{64}$ STEIN, Sofia Inês Albornoz. O empirismo e a ontologia das ciências naturais. FILOSOFIA: UNISINOS, maio/ago 2007. p. 130. 
parte, as condições para afirmar que as sentenças observacionais se constituem deste modo na medida em que se estabelece uma relação entre elas, o que denomina "estímulos" como espécie de "moldes de irradiação" ou, como surgiram ao longo do texto, "entradas neurais globais". Desta feita, Quine supera a tradição de filósofos empiristas e racionalistas quando estabeleceram como navalha de corte a distinção entre enunciados verdadeiros a priori e enunciados verdadeiros devido à experiência e apropria-se de certa possibilidade empírica em consonância com seus enunciados observacionais que melhor determinam o objeto cientifico (holismo moderado).

A instabilidade gerada por um discurso eu se apóia na Ciência de modo empírico apenas representa perigo quando alem de desejado socialmente é assumido pelo Estado e instaura um processo político-institucional que coloca sob ameaça os direitos fundamentais constituídos juridicamente, inclusive em Itaguaí. Na busca da adequação de políticas públicas à visão cientifica por meio de um método empírico baseado em enunciados observacionais surgem palavras como terror, restauração, assombro e rebelião, entretanto, na origem o alienista estava apenas estudando a loucura, a fim de produzir uma teoria nova. No percurso trilhado pelo alienista evidencia-se o fato de que a ciência pura não é garantia humanidade e progresso social.

\section{REFERÊNCIAS BIBLIOGRÁFICAS:}

AMARANTE, P. D. de C., (coordenador), Loucos pela vida: a trajetória da reforma psiquiátrica no Brasil. Rio de Janeiro, FIOCRUZ, 1995.

AYER. A.J. (Org.) NEURATH, Otto. IX. Preposiciones protocolares. In. El positivismo logico. Madrid, 1993.

BRASIL. Ministério da Saúde. Reforma Psiquiátrica e política de Saúde Mental no Brasil. Secretaria de Atenção à Saúde. DAPE. Coordenação Geral de Saúde Mental. Reforma psiquiátrica e política de saúde mental no Brasil. Documento apresentado à Conferência Regional de Reforma dos Serviços de Saúde Mental: 15 anos depois de Caracas. OPAS. Brasília, novembro de 2005.

BRASIL. Programa de Volta para Casa .Disponível em: www.ccs.saude.gov.br/VPC/programa.html, acesso em 25 de Maio de 2013.

BRASIL. Reforma Psiquiátrica ou Luta Antimanicomial. Disponível em: http://pfdc.pgr.mpf.gov.br/atuacao-e-conteudos-de-apoio/publicacoes/saudemental/direito_saude_mental_2012/http://pfdc.pgr.mpf.gov.br/atuacao-e-conteudos-deapoio/publicacoes/saude mental/direito_saude_mental_2012/, acesso em 25 de Maio de 2013. 
CANGUILHEM,G. O normal e o patológico, trad. Maria Thereza Redig de Carvalho Barrocas e Luiz Octavio Ferreira Barreto Leite. - 4a. Ed.- Rio de Janeiro, Forense Universitária.

KRAFT, Victor. El Circulo de Viena. Editora TAURUS: MADRID, 1986.

MACHADO DE ASSIS, Joaquim Maria. O alienista. Porto Alegre: LPM, 2010

POPPER, Karl. Lógica da Pesquisa Cientifica. Editora Cultrix: São Paulo, 1972.

ROCHA, Gilberto S. - Introdução ao nascimento da psicanálise no Brasil. Rio de Janeiro,Forense Universitária, 1989.

STEIN, Sofia Inês Albornoz. Van Orman Quine. Epistemologia, semântica e ontologia. Filosofia das Ciências. Porto Alegre, 2009.

, Sofia Inês Albornoz. Palavra e Objeto. Vozes: Petrópolis, RJ. 2010.

, Sofia Inês Albornoz. A dimensão metafísica da inescrutabilidade da referência.

FILOSOFIA: UNISINOS, 2006.

Sofia Inês Albornoz. O empirismo e a ontologia das ciências naturais. FILOSOFIA:

UNISINOS, maio/ago 2007. 